\title{
Control of astigmatism after surgery and trauma: a new technique
}

\author{
M J ROPER-HALL AND A D ATKINS \\ From the Birmingham and Midland Eye Hospital, Birmingham
}

SUMMARY Five patients were subjected to a new technique designed to correct high astigmatism not responding to suture removal or adjustment. The method is described and its use illustrated in five case histories. Four of the five cases were successfully treated. The reasons for the one failure are discussed. All procedures were uncomplicated. The technique is simple, safe, and reversible.

Despite safe surgical technique and generally accurate microsurgical wound closure some patients are found to have unacceptably high astigmatic errors. Some of these errors are amenable to the selective removal of overtight sutures, the adjustment of a continuous suture, or both.'

However, in a number of cases of astigmatism these methods cannot be applied. There are several possible reasons: (1) All the sutures have already been removed. (2) The wrong sutures have been removed, making the astigmatism worse. (3) The initial injury caused so much scarring and traction that suture removal has no effect. (4) The sutures are buried, as in a standard corneoscleral section, under a limbal-based conjunctival flap. (5) Adjustment of a continuous suture has failed.

In these unfortunate patients further surgery may be required. Fyodorov ${ }^{2}$ reintroduced methods of keratotomy and has described its use in the correction of astigmatism as well as refractive errors. Final results have not been predictable, with high errors, and there may be complications. ${ }^{3}$ Any surgical procedure involving cutting the cornea or removing a wedge $^{3}$ is irrevocable, and if the outcome is unsatisfactory it is not reversible.

\section{Material and methods}

\section{CASE SELECTION}

Our five cases consist of: (1) One case of astigmatism following keratoplasty (case 1). (2) Three cases of astigmatism following routine cataract extraction with four-loop Binkhorst intraocular lens insertion (cases 2, 3, and 4). All three were subjected to adjustment of their continuous sutures,' but the Correspondence to Mr M J Roper-Hall, FRCS, Birmingham and Midland Eye Hospital, Church Strect, Birmingham B3 2NS. procedure failed to correct their astigmatism. Two of these cases were part of a group of 36 such adjustment cases; the remainder were managed successfully without resorting to resuture. The results of these 36 cases are reported separately. ${ }^{4}$ (3) One case of penetrating trauma to corneosclera and lens. This case stands out as a separate problem and is presented last.

\section{METHODS}

After appropriate anaesthesia (our patients were treated under general anaesthesia) a superior rectus bridle suture is placed to control the position of the eye. Interrupted $9 / 0$ nylon sutures are placed at $2 / 3$ rds depth in the clear peripheral cornea at and around the axis of the negative cylinder. The lengths of bite were $2-3 \mathrm{~mm}$. For example: refraction $+2 \cdot 00$ D.sp/-7.00 D.cyl axis $60^{\circ}$ (Fig. 1).

Tight $9 / 0$ nylon sutures will be placed as shown. They are placed in two rows on both ends of the $60^{\circ}$ meridian. The first tie of the suture has three throws and is pulled tight enough to show stress in the cornea. This steepens the cornea sufficiently to convert the minus to a plus axis in the same meridian. An assistant holds the tie while the knot is completed with single throws to make it secure. The excess is cut off short with a sharp blade and the suture rotated to bury the knot in the suture track. Several knots are inserted, with the aim of overcorrecting the astigmatism at the time of surgery. This could well result in a 10-15 dioptre change in astigmatism and cause the eye in this example to have an early postoperative cylinder of 5 dioptres with a plus axis at the same $60^{\circ}$ meridian - that is, a change of 12 dioptres. This allows for the reduction in the cylinder, as the effect degrades during a four to six weeks postoperative course. If necessary further adjustment is made after 


\section{CORNEAL SUTURING TECHNIQUE - EXAMPLE}

\section{BEFORE SUTURING}

$-7.00 \times 60^{\circ}$

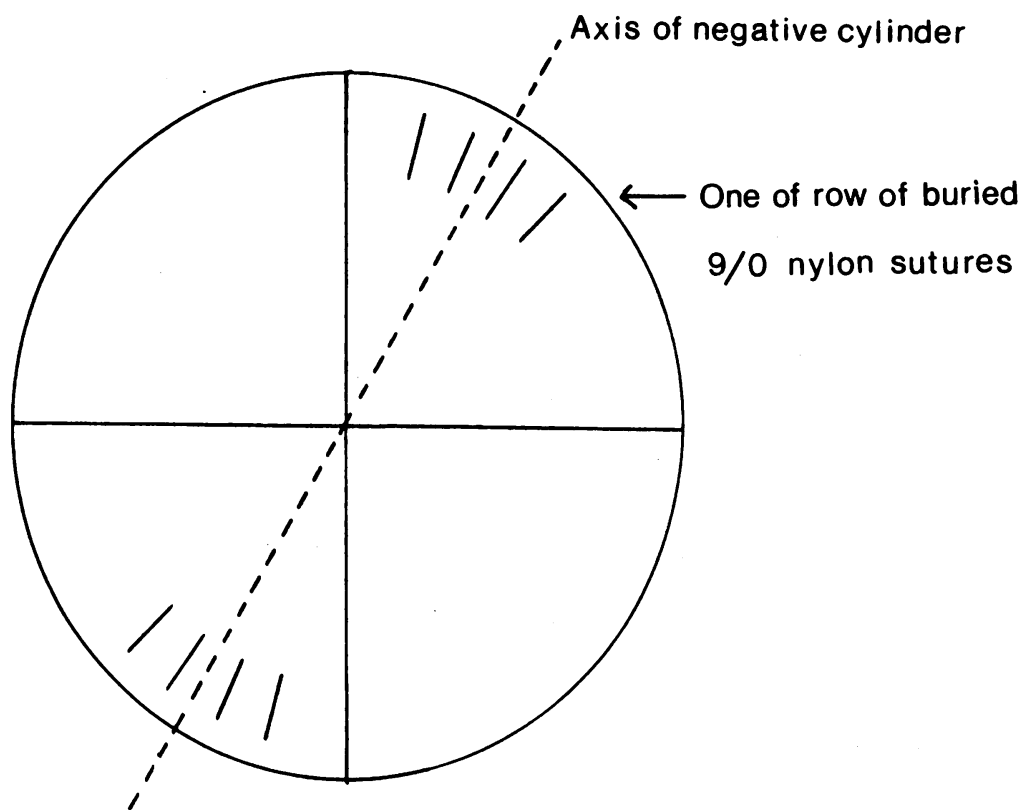

Fig. 1 Example of corneal suturing technique. A cylinder of $-7.00 \times 60^{\circ}$ would be treated by placing $9 / 0$ nylon sutures tightly in clear cornea around the $60^{\circ}$ axis (i.e., the axis of the negative cylinder) to steepen this meridian. The knots must be buried.

\section{BEFORE}

$-10.00 \times \underline{180^{\circ}}$

AFTER ONE DAY

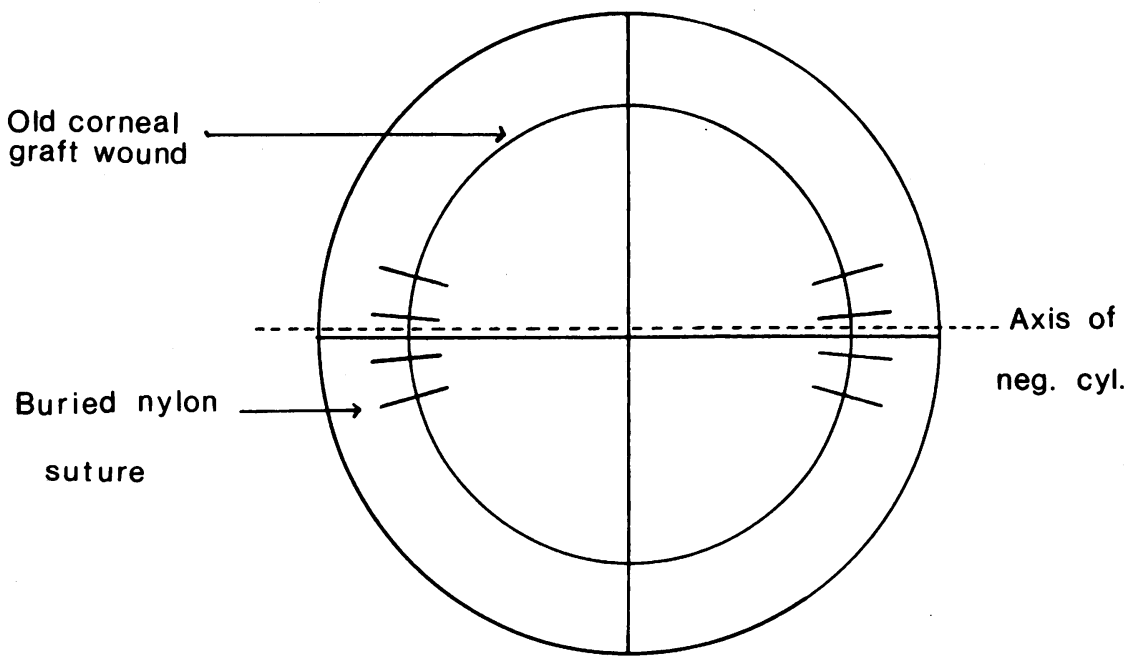
graft wound

$-10.00 \times \underline{85^{\circ}}$

Fig. 2 Case 1. A female aged 28 years, underwent penetrating keratoplasty in June 1981 for corneal scarring following herpes zoster ophthalmicus. In February 1982 indiscriminate removal of all sutures in an attempt to correct 5.00 dioptres astigmatism actually produced a 10.00 dioptre cylinder axis $180^{\circ}$. Interrupted sutures as shown shifted the axis to $85^{\circ}-$ a change in astigmatic power of 20.00 dioptres. 
not less than four weeks by removing some of the newly placed individual sutures, which are now in the axis of the positive cylinder, and checking the refractive error between each removal until a satisfactory refraction is obtained. Experience has shown that it is often wise to make this adjustment over a period of a few weeks, only a single suture being removed at any one time. The optimum time for this adjustment seems to be between four and eight weeks after the tensioning sutures have been placed. The remaining sutures are left in situ.

We must stress that the tensioning sutures are placed in the negative axis, with the aim of overcorrection, and delayed single suture removal is in the same axis, which is then positive.

We have found $9 / 0$ nylon to be most reliable; with finer gauge, tension may not be sufficient before the suture breaks. It is wise to warn the patient that surgery is aiming at an overcorrection. The refraction should be observed during the early postoperative course and removal of sutures firmly resisted until this observation has been sufficient for early moulding to have become stable. This period serves a similar purpose to that described previously. ${ }^{1}$

\section{Case reports}

CASE 1 (Figs. 2, 3)

A female aged 28 years suffered right herpes zoster ophthalmicus with subsequent scarring. 10 June 1981: right penetrating keratoplasty, $7.5 \mathrm{~mm} .18$ February 1982: $+4 \cdot 25$ D.sp/-5.00 D.cyl axis $100^{\circ}=$ $6 / 18$.

Unfortunately all the sutures were removed indiscriminately without reference to the axis of astigmatism, resulting in +3.00 d.sp/ $-9.00 \mathrm{D}$.cyl axis $20^{\circ}$. 21 June 1982: refraction still -0.50 D.sp/ -10.00 D.cyl axis $180^{\circ}$.

Interrupted sutures were placed in her cornea (Fig. 2) under general anaesthesia round the axis of the negative cylinder. One day later: $+6 \cdot 50$ D.sp $/-10 \cdot 00$ D.cyl axis $85^{\circ}$ - that is, a change of cylinder of 20.00 dioptres. Between one and six weeks later single sutures were removed in the axis of the positive cylinder until her refraction was plano/-2.00 D.cyl axis $70^{\circ}$.

She has subsequently retained the small cylinder, and on 9 June 1983, twelve months later, her refraction was $-0.50 \mathrm{D} . \mathrm{sp} /-2.00 \mathrm{D}$.cyl axis $50^{\circ}$.

\section{One week after suturing}

$$
-9.50 \times 87 \frac{1}{2}
$$

Between one and Six weeks after suturing, selected suture removal around positive axis (dashed lines).

After suture removal:

$$
-2.00 \times 70^{0}
$$

Twelve months after suturing

$-2.50 \times 50^{0}$

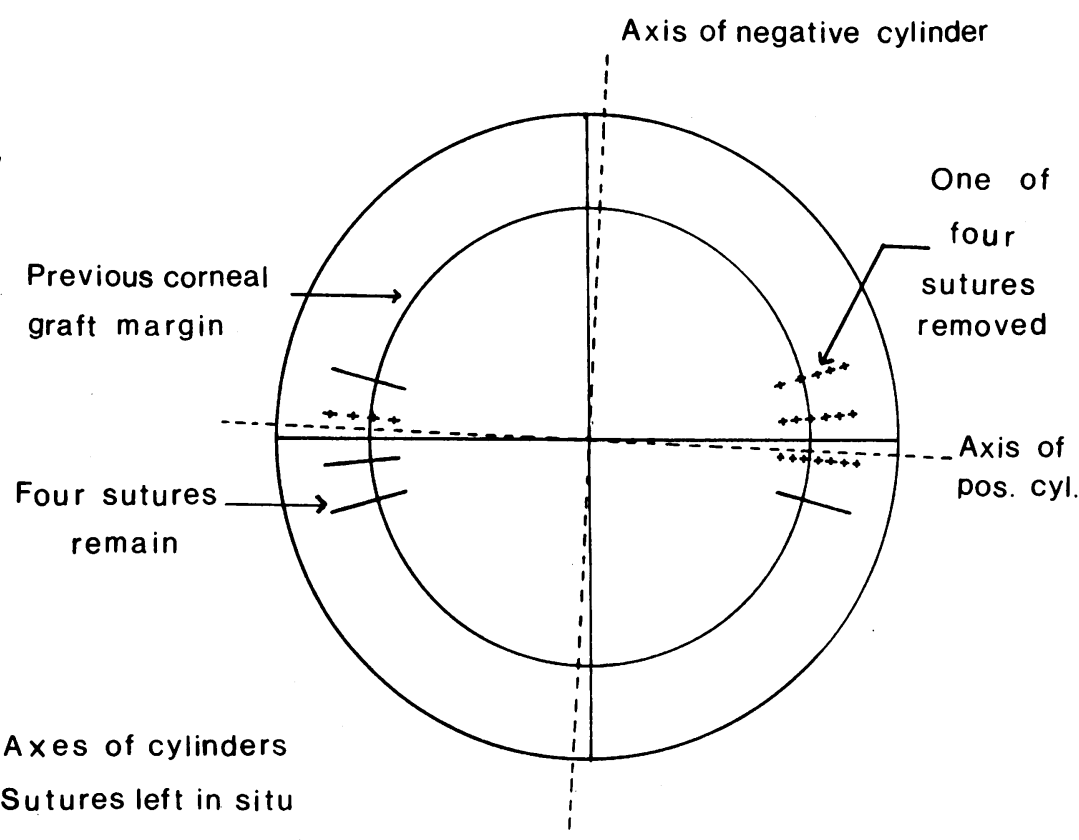

\section{++++ Sutures removed}

Fig. 3 Case 1. Between one and six weeks after suturing, selected sutures (shown as dashed lines) were removed around the line of the positive axis. The cylinder was checked between each removal until her refraction revealed 2 dioptres of astigmatism at six weeks. A year after suturing her cylinder is $-2 \cdot 00 \times 50^{\circ}$. 


\section{COMMENT}

The initial dramatic effect of the suturing can be seen, with a shift of the axis of astigmatism through $90^{\circ}$ and a total change of 20 dioptres. Deliberate overcorrection was followed by cautious suture removal. Definitive adjustment was delayed for six weeks, to result in a 2.00 dioptre astigmatism still in the axis of the overcorrection. Her refraction has remained remarkably stable since then. Suture removal would have been equally effective and safer if begun at eight weeks.

\section{CASE 2 (Fig. 4)}

A female aged 68 years. 10 August 1982: left intracapsular extraction (corneal section) with four-loop Binkhorst intraocular lens. 14 October 1982: -1.00 D.sp/-5.00 D.cyl axis $100^{\circ}$. Suture adjustment was attempted as described previously' but failed to improve her astigmatism, and the corneal suture was removed: -3.00 D.sp/-5.00 D.cyl axis $90^{\circ}$. 18 January 1983: sutures were placed in the cornea (Fig.
4) with a resulting axis shift through $90^{\circ}:-5.00$ D.sp/ $-2 \cdot 00$ D.cyl axis $180^{\circ}=6 / 6$.

Two weeks later the cornea was spherical and no suture removal was indicated. Four months later her refraction was still satisfactory: $-4 \cdot 50 \mathrm{D} . \mathrm{sp} /-2 \cdot 00$ D.cyl axis $95^{\circ}=6 / 5$. 7 July 1983: six months after suturing had been undertaken a doctor unaware of our intention of long-term retention removed all the sutures. Fortunately in this case there was only a small change, and on 13 October 1983: -4.50 D.sp/ -2.50 D.cyl axis $97^{\circ}=6 / 6$ was found on refraction.

\section{COMMENT}

Overcorrection in this patient was small, and suture removal at six months carried a risk of recurrence of the original excessive error. However, the cornea in this case seems to have reached a stable form, and suture removal was not as unfortunate as expected. There is still a general misconception that corneal sutures need to be removed. It is emphasised that a

\section{BEFORE SUTURING}

$-5.00 \times 90^{0}$

Two days after

$$
-2.00 \times 180^{\circ}
$$

Two weeks after.

No astigmatism

Four months after

$-2.00 \times 95^{0}$

Nine months after

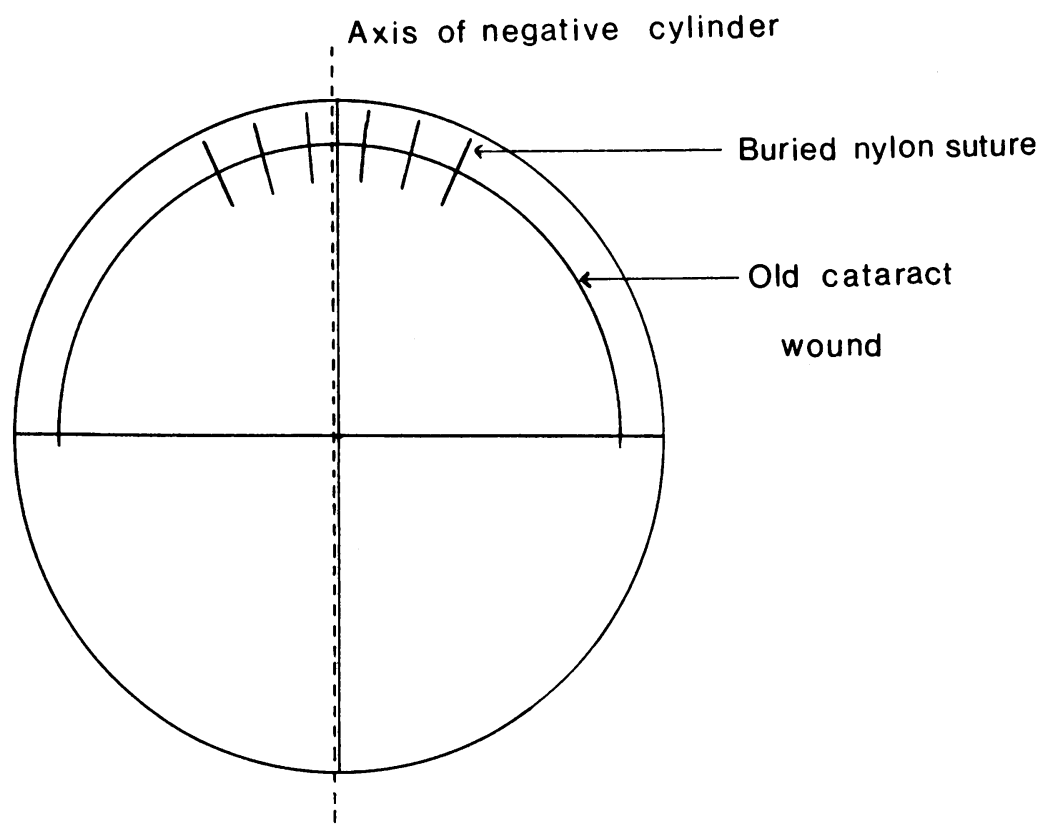

$$
-2.50 \times 97 \frac{1}{2}^{\circ}
$$

Fig. 4 Case 2. A female aged 68 years, had astigmatism following cataract extraction with insertion of intraocular lens. The astigmatism failed to respond to adjustment of the corneal continuous suture (see text) and the suture was removed. Interrupted nylon sutures were placed around the negative cylinder axis as shown, moving the axis through $90^{\circ}$. Two weeks later the cornea was spherical. Four months later the cylinder was $-2.00 \times 95^{\circ}$. Nine months after suturing the cylinder was $-2.50 \times 971 / 2^{\circ}-$ that is, minimal change despite early removal of sutures (see text). 
tightly organised follow-up is needed by those who are aware of the procedure and what it is intended to achieve.

\section{CASE 3 (Fig. 5)}

A male aged 65 years. 15 November 1977: right intracapsular extraction (corneal section) with fourloop Binkhorst intraocular lens insertion. 15 February 1978: +4.00 D.sp/-7.50 D.cyl axis $75^{\circ}$ (adjustment and suture removal had failed). 25 February 1978: suturing of cornea (Fig. 5) in the axis of the negative cylinder. Initial overcorrection to $+3 \cdot 50 \mathrm{D} . \mathrm{sp} /-6 \cdot 50 \mathrm{D}$.cyl axis $130^{\circ}$.

After single suture removal on 17 March 1978 his refraction was $+1.50 \mathrm{D} . \mathrm{sp} /-3.00 \mathrm{D}$.cyl axis $105^{\circ} .21$ March 1983: five years later (with frequent checks over the years showing stability) his refraction was still $+1 \cdot 50$ D.sp/ $-3 \cdot 00$ D.cyl axis $97^{\circ}=6 / 5$.

\section{COMMENT}

Initial overcorrection was adjusted after three weeks with a satisfactory long-term result. We would wait longer now before adjusting.

CASE 4 (Fig. 6)

A male aged 70 years. 30 July 1982: right intra- capsular extraction (corneal section) with four-loop Binkhorst intraocular lens insertion. 30 September 1982: continuous suture adjustment for $3 \cdot 50$ dioptres of astigmatism was attempted, but the suture broke and was removed. Immediate refraction was -5.00 D.sp/-1.00 D.cyl axis $90^{\circ}$. Three weeks later on 21 October 1982: +1.00 D.sp/-7.00 D.cyl axis $70^{\circ}$. A row of sutures (Fig. 6) was placed round the axis of the negative cylinder giving an initial result on 28 October 1982: +0.75 D.sp/-0.50 D.cyl axis $60^{\circ}$. Four weeks later on 25 November 1982: -1.75 D.sp/-1.25 D.cyl axis $90^{\circ}$. In December 1982 he died from a severe cerebrovascular accident.

\section{COMMENT}

This amount of corneal moulding (6 dioptres) after suture removal eight weeks after operation is unusual in our experience.

This man's tragic death prevented longer followup, but his case demonstrates slight undercorrection of the astigmatism-less reliable than initial overcorrection.

CASE 5 (Figs. 7 and 8 )

A male aged 45 years sustained a perforating injury to his right eye in June 1978. The resultant cataract

\section{BEFORE SUTURING}

$$
-7.50 \times 75^{\circ}
$$

AFTER: $-6.50 \times 130^{\circ}$

3 Weeks later, after selected suture removal (not shown)

$$
-3.00 \times 105^{0}
$$

Five years later

$$
-3.00 \times 97^{\circ}
$$

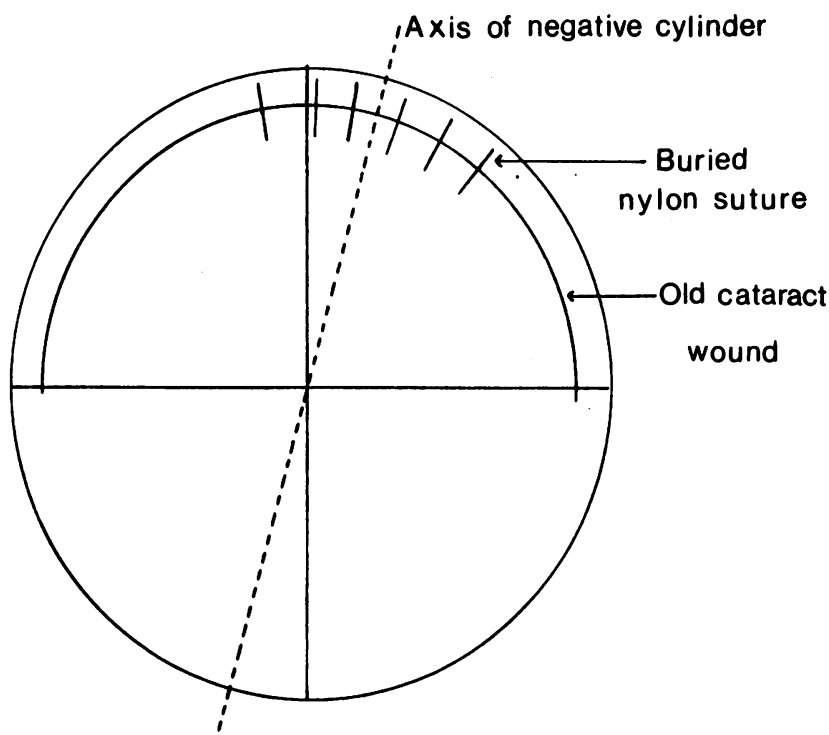

Fig. 5 Case 3. A male aged 65 years, had astigmatism following cataract extraction and intraocular lens insertion. Suture adjustment failed (see text) and the corneal sutures were removed, following which he still had 6.50 dioptres astigmatism. Buried nylon sutures were placed around the negative cylinder axis as shown, resulting in an axis shift from $75^{\circ}$ to $130^{\circ}$. Three weeks later selected sutures were removed in stages until astigmatism was only 3.00 dioptres. Five years later he retained a refraction of $-3.00 \times 9706 / 5$. 


\section{BEFORE SUTURING}

$-7.00 \times 70^{\circ}$

AFTER

$-0.50 \times 60$

Four weeks later

$$
-1.25 \times 90^{0}
$$

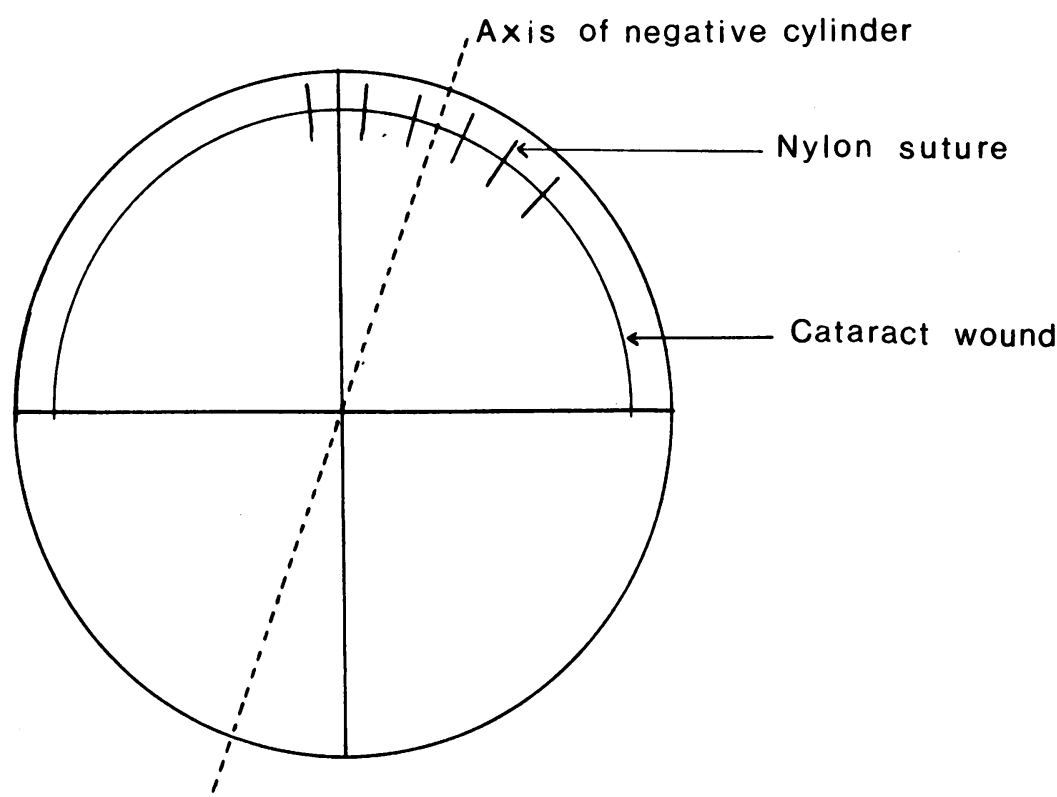

Fig. 6 Case 4. A male aged 70 years, developed astigmatism following cataract extraction using a continuous corneal suture. Suture adjustment was attempted at eight weeks after operation, but the suture broke. Over the next three weeks the cylinder increased to $-7.00 \times 70^{\circ}$. Interrupted sutures were placed around the negative cylinder axis, and after one week the cylinder was $-0.50 \times 60^{\circ}$. A month later, eight weeks after suturing, the cylinder was $-1.25 \times 90^{\circ}$. Further follow-up was prevented by his death from a cerebrovascular accident.

was removed in September 1981, but he had high astigmatism from the original scarring. 5 October 1982: +15.00 D.sp/-7.00 D.cyl axis $85^{\circ}$. His cornea was sutured with buried 10/0 nylon around the negative cylinder axis (Fig. 4). Subsequent refraction was $+14.00 \mathrm{D} . \mathrm{sp} /-5.00 \mathrm{D}$.cyl axis $160^{\circ}$, a significant axis shift.

4 November 1982: interrupted sutures were removed in the axis of the new positive cylinder (Fig. 5) with an encouraging initial result: $+15 \cdot 00$ D.sp/ -2.00 D.cyl axis $90^{\circ}$. 6 January 1983: his refraction had unfortunately changed to $+17 \cdot 00$ D.sp/ $-7 \cdot 00$ D.cyl axis $80^{\circ}$.

14 April 1983: the cornea was resutured in the same manner as before. Next day: +17.00 D.sp/ -7.00 D.cyl axis $165^{\circ}$. One suture was removed: +15.00 D.sp/-6.00 D.cyl axis $120^{\circ}$. 9 June 1983: +15.00 D.sp/-5.00 D.cyl axis $110^{\circ}$; he had reverted to his original astigmatism.

\section{COMMENT}

The failure of both attempts at correction was probably explained by the large traumatic scar, which was more difficult to mould than keratoplasty or cataract sections. In addition the 10/0 suture material was too weak and the sutures were removed too early after both attempts. 9/0 Material is preferable.

\section{Discussion}

These suturing procedures were uncomplicated both at the time of surgery and afterwards. The procedure is simple enough to require minimal skill, provided an operating microscope is used and the sutures are placed with care. It is perhaps less easy to decide where the sutures should be placed, how many, and when they should be removed to obtain the desired long-term result. The case reports show that changes continue for some time, and it is important to exercise patience before making the definitive 'final' adjustment. The procedure is essentially reversible, and it is intended that some sutures are left in place until they degrade and fragment some two years later. By that time it seems that the refraction will have stabilised without the suture support. In case 5 a number of factors contributed to this one failure: (1) the suture used was too thin; (2) sutures were removed too early; (3) the astigmatism was due to 


\section{BEFORE SUTURING}

$-7.00 \times 85^{\circ}$

\section{AFTER \\ $-5.00 \times{\underline{160^{\circ}}}^{\circ}$}

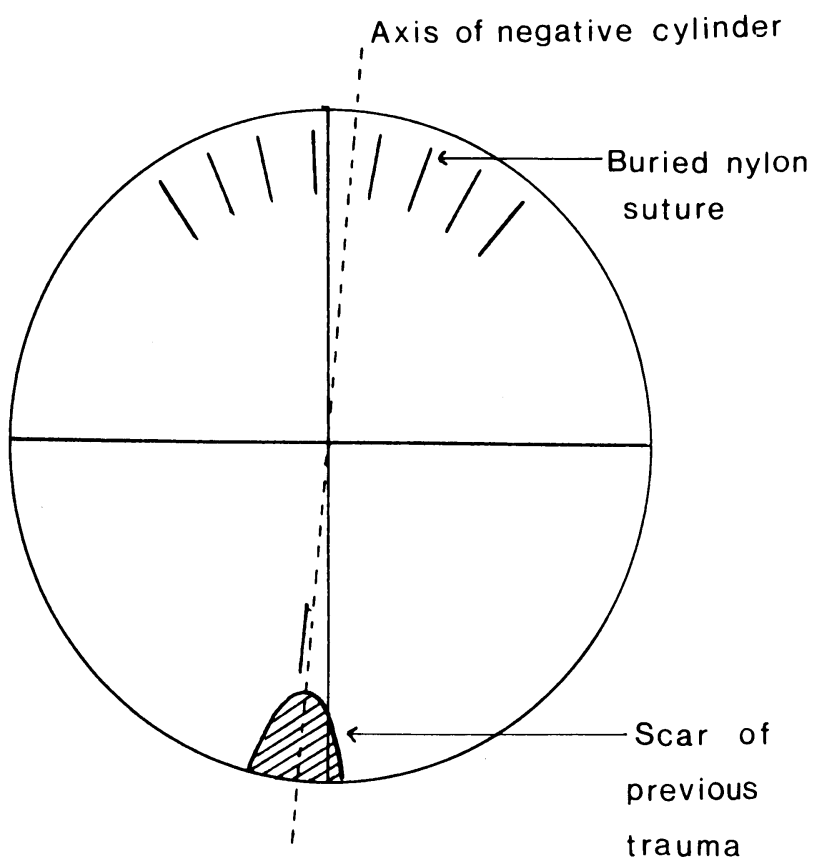

Fig. 7 Case 5. A man aged 45 years, sustained a perforating injury with lens damage in June 1979. His lens was removed in September 1981, but astigmatism of 7.00 dioptres remained after 28 months despite removal of corneal sutures in cataract section. A row of buried 10/0 nylon sutures were placed around $85^{\circ}$ (the negative axis) overcorrecting the astigmatism to $-5.00 \times 160^{\circ}$.

\section{Before suture removal}

$-5.00 \times 160^{0}$

\section{After removal}

$$
-2.00 \times 90^{\circ}
$$

Two months later

$-7.00 \times 80^{\circ}$

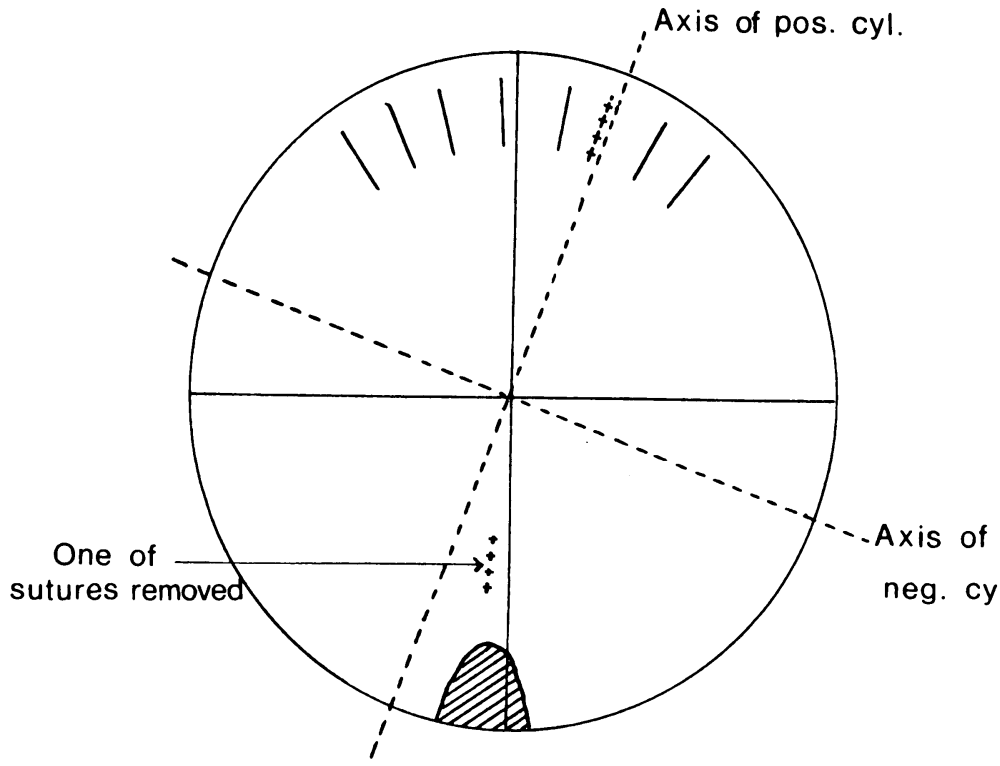

Fig. 8 Case 5. The new negative ana itive axes are shown. One week after suturing, two sutures, shown dashed, were removed, giving an initial encouraging result of 2 dioptres. However, the suture material was too weak and the sutures were removed too early. Two months later the astigmatism was back to $-7.00 \times 80^{\circ}$. A further attempt at suturing was also unsuccessful (see text). 
trauma and subsequent reparative surgery, resulting in two corneal wounds with complex stresses. The cornea was probably less able to undergo corneal moulding than the other cases which were routine keratoplasty or cataract sections.

From our experience of the cases described above and others in which selected suture removal or adjustment can not be applied we recommend overcorrection of the astigmatism by suturing in uncut cornea with $9 / 0$ nylon in the negative cylinder axis. After waiting 4-8 weeks for corneal moulding one selected suture is removed at a time in the new positive axis and the refractive error rechecked. 2-3
Dioptres should be left in the new axis to allow for further decay.

\section{References}

1 Roper-Hall MJ. The control of astigmatism after surgery and trauma: Br J Ophthalmol 1982; 66: 556-9.

2 Fyodorov S. Surgical correction of myopia and astigmatism. In Schachar RA, Levy NS, Schachar L, eds. Keratorefraction. Proceedings of the Keratorefractive Society. Denison, Texas, PO Box 145, 1980: 141-72.

3 Troutman RC. Microsurgical control of corneal astigmatism in cataract and keratoplasty. Trans Am Acad Ophthalmol Otolaryngol 1973; 77: 563-72.

4 Atkins AD, Roper-Hall MJ. Control of postoperative astigmatism. BrJ Ophthalmol 1985; 69: 348-51. 